\title{
Challenges of Adults in Learning English as a Second Language: Focus on Adult Education in China
}

\author{
Ruijuan $\mathrm{Wu}$ \\ Hebei United University, Tang Shan, Hebei, China \\ Ruiting Wu \\ Faculty of Education, University of Tasmania, Launceston, TAS, Australia \\ Van Tai Le \\ The Tasmanian School of Business and Economics, University of Tasmania, Hobart, TAS, Australia
}

\begin{abstract}
Adult education functions significantly in Chinese education. Adults' ESL learning especially plays an important role on the development of China and of the adults themselves. This study aimed to discover challenges and problems of Chinese adults' ESL learning, and the solutions to these problems. A random sample of 50 Chinese adult ESL learners was used. The data gathering consisted of a questionnaire, and the data analysis employed both quantitative and qualitative methods. The findings confirmed that ESL learning is very important for Chinese adults' future life. However, they have experienced many difficulties and problems when pursuing ESL learning, regardless some advantages they may have over children. Many suggestions were thus made to improve adults' ESL learning.
\end{abstract}

Index Terms - ESL learning, adult education, advantages and problems of adults' ESL learning

\section{INTRODUCTION}

In terms of adults' learning, we need to know what "adult" refers to. However, it is difficult to define "adult" since there is "no particular arrangement of criteria" (Little, McAllister \& Priebe, 1991, p. 22). People who reach the legal age of adults are given the right of voting and getting a driving license and marriage, but they may not be independent psychologically or economically to live in society, while people who do not reach this legal age may be mature enough for work. However, puberty is generally viewed as "a key point for differentiating between children and adults" (Brown, 1991, p. 25). After puberty, people become adults biologically.

In China, the legal age of an adult is 18 years old. However, the adult education in China is not defined according to age. For example, undergraduates are usually aged from 19 to 25, but they do not belong to adult education because they were registered in high schools before entering universities. Actually, adult education in China is for students who are not currently registered in high schools, but want to study further in higher education.

Adult education, especially teaching and learning English as a second language (ESL), functions significantly in Chinese education. The adults' ESL learning is very different from children's. In some aspects, adults may have some advantages over children. However, as Richard-Amato (1996, p. 25) said, "being older is not always advantageous in learning a second language". During the process of ESL learning, Chinese adults will definitely encounter many problems. The solutions to these problems should thus be discovered.

\section{THE RESEARCH Aim AND THE QUESTIONS}

The main aim of this study was to discover challenges and problems of Chinese adults' ESL learning, and the solutions to these problems. This study pursued the following four questions in order to achieve this aim:

1. What are the Chinese adults' views on the reasons of their pursuing ESL learning?

2. What are the Chinese adults' views on the advantages of ESL learning that adults may have over children?

3. What are the Chinese adults' views on the problems of their ESL learning?

4. What are the Chinese adults' views on how to improve adults' ESL learning?

The findings from this study are helpful for Chinese ESL adult learners to improve their ESL learning. This study will strengthen research in the fields of adult education and ESL learning.

\section{THE SIGNIFICANCE OF THE RESEARCH}


"Continuing education is an important function of higher education institutions" (Center for Educational Research and Innovation, 1987, p. 89). It may be more important than a child's education since a person's time in adulthood is usually longer than in childhood and teenage, based on 18 years legal age as an adult, and adults are generally more than children in population. Therefore, adult education gives more contribution in the promotion of citizen's attainments. Moreover, a country's development depends on every citizen's contribution. "As the technology becomes increasingly complex and sophisticated, the economy will require more highly skilled people in order to operate these machine systems and put them to their most productive use" (Center for Educational Research and Innovation, 1987, p. 17). Without learning, skills and knowledge cannot be achieved. People thus cannot work technologically. If the citizen's literacy level is very low, it is very difficult for the country to develop.

Adult education is especially important in China since the average literacy level of Chinese citizens is too low. According to the 2001 China's national census (Zong Shi, 2002; Xie Guodong \& Du Yue, 2002), more than 85,070,000 citizens are illiterates or know very few Chinese characters, and most of them are over 15 years old. Therefore, adult education is especially important in the promotion of Chinese citizen's attainments and the development of China.

\section{LITERATURE REVIEW}

Adult ESL learning is very different from that of children who rely much on highly visual websites with interactive games, and require English lessons to be fun and rewarding (Graddol, 2006). Adult ESL learners have their unique difficulties that are different from that of children. The difficulties need to be identified. Teaching approaches and learning strategies that are suitable for adults' learning also need to be researched. In the adult ESL education literature, adult education principles, guidelines for practice, and some of the distinctive difficulties that adult ESL learners have in the classroom were described (Brod, 1995; California State Department of Education, 1993; Crandall \& Peyton, 1993; Ramirez, 1994; Smoke, 1998; Weinstein-Shr, 1993; Wrigley \& Guth, 1992). However, Norton Peirce $(1995,2000)$ claimed that little research addressed on the complex relationships among adult learners' identities, the social contexts of their daily lives, the classroom context, and investment in learning English. Moreover, a number of studies (Levy, Osborn \& Plunkett, 2003; Spencer-Oatey \& Xiong, 2006; Wong, 2001; Wu, 2013) have examined difficulties of Chinese speaking adults who were living in an English-speaking country, and learning strategies to survive or even succeed in studying overseas. Surprisingly, it appears that few studies concerned Chinese adults who live in China, while this number of group is much larger than that of people who live overseas. The present research thus seeks to find out the problems that Chinese adults in China have in ESL learning and solutions to these problems.

\section{Methodology}

This study was based on a survey design. The data gathering consisted of a questionnaire (see Appendix). The first three research questions were examined through the closed questions of the questionnaire, which was the first step in the data collection. The open-ended questions further explored the first three research questions and also investigated the fourth research question.

This study recruited fifty (50) Chinese adult ESL learners. They were 25 males and 25 females. Hard copies of questionnaires and details of the study were posted to potential participants. The data analysis in this study employed both quantitative and qualitative methodological methods. The analysis of the questionnaires focused on answering the research questions. This data analysis also involves discussion of issues generated from the data and whether they are supported or refuted in existing literature related to this topic.

\section{FINDINGS}

In this research study, all of the 50 questionnaires distributed were completed and returned by the participants. All of the 19 closed questions were answered, whilst the four open-ended questions received 25 responses for each question. According to the responses from the participants, differences in gender, age, and length of learning English were not found in the views being questioned. It was commonly acknowledged by the participants that ESL learning is very important for their future life, and they did experience difficulties and problems when pursuing ESL learning, although they may have some advantages over children. Many suggestions were also made to improve adults' ESL learning.

\section{DISCUSSION}

This section will analyse the findings in relation to the research questions. When citing a participant, the participant is coded as "QP A", "QP B" or "QP C", and so on.

What are the Chinese adults' views on the reasons of their pursuing ESL learning?

According to the responses from 50 questionnaires, most of the participants (90\%) marked "agree" or "strongly agree" on the view that the Chinese government highly emphasizes ESL learning in China. As the participants stated:

The English exam is compulsory for students for all entrance exams to a higher school, such as the senior high school entrance exam, the undergraduate entrance exam and the postgraduate entrance exam. Each student who wants to study further for a Master's and a Doctor's degree must achieve a score of 50 out of 100 in the English exam no 
matter which major he/she studies. Otherwise the student is not offered an enrolment in postgraduate study no matter how well he/she has done in other subjects (QP A).

The English exam is compulsory for teachers at all levels of schools and universities to get a higher professional title and promotion. Teachers in all schools and universities must achieve 60 per cent in the English exam held in their local province to get the permission and qualification for a higher professional title, such as lecturer and professor. No matter how hard or how well the teachers have worked, they cannot be promoted to a higher position if they fail the English exam $(Q P B)$.

Most of the participants (over 80\%) also agreed that English is very important for Chinese adults to compete in the labor market and English is an important means for Chinese people to earn money.

What are the Chinese adults' views on the advantages of ESL learning that adults may have over children?

Many participants $(78 \%)$ indicated that adults concentrate on learning more easily than children. According to a participant's statement:

When I studied English night class after I had already worked during the day in a secondary school, to my surprise, my mind did not wander away during the lesson as usual. My attention kept concentrating on the class and the efficacy was much higher than when I studied in primary and high schools (QP C).

This point of view was supported by Harmer (1991, p. 7) who noted, “adults' concentration span is generally longer than children's".

Nearly all participants (96\%) revealed that adults usually take more responsibility for the learning process and are more active in learning than children. This opinion reflected a similar opinion to Ur (1996, p. 295) who said that "most adults come to the class voluntarily, while most children are given no choice".

Most of the participants $(90 \%)$ indicated that adults have stronger motivation in learning English than children. A questionnaire of 300 adult English learners conducted by Wu Huifang (2002) showed that about 70 per cent Chinese adults learned English for a better job. Graddol (2006, para. 3) also pointed out, "young children don't usually have the kind of instrumental motivation and determination for learning English that older learners often have (though their parents and relations may)".

$80 \%$ of participants said that adults' cognitive ability is greater than children's and adult ESL learners have a greater knowledge of the world in general and more experiences. As a participant stated:

I feel that I am more intelligent than when I was young. When I read the books of primary school, to my surprise, I find it so simple. Is this what I found too difficult to learn in primary school? (QP D)

This viewpoint was supported by Graddol (2006, para. 3) who noted, "young learners have less experience at learning and so fewer cognitive strategies for remembering things, or coping with the discouraging setbacks that are typical of any learning curve". Brown (1994: 90) also noted, "[adults] can utilize various deductive and abstract processes to shortcut the learning of grammatical and other linguistic concepts".

What are the Chinese adults' views on the problems of their ESL learning?

A large majority of participants (94\%) agreed that adults especially find difficulty in obtaining a native-like accent, and adults who missed ESL learning thus lose confidence. The statistics conducted by Seliger (as cited in Wu Biyu, 2005 ) reported that only $6 \%$ to $8 \%$ of adults might have no first language accent in second language learning. Linguists as well as the general public often share the point of view that "one started learning English as a second language as an adult never managed to learn it properly, and another who learns it as a child is indistinguishable from a native" (Cook, 1991, p. 83). In fact, "the differences of accent, word choice, or grammatical features usually set adults apart from native speakers or from speakers who began learning the language while they were very young" (Lightbown \& Spada, 1993, p. 42).

$76 \%$ of participants indicated that adults often find it stressful when they are unable to express themselves clearly and correctly in a second language. According to Wong (2006), adults may feel very embarrassed about being students again for the feeling of being old and away from school for many years. A questionnaire of 300 adult English learners conducted by Wu Huifang (2002, p. 61) showed that "about 80 per cent Chinese adults felt embarrassed or ashamed of making mistakes". Lightbown and Spada also said (1993, p. 42), "adults are often embarrassed by their lack of mastery of the language".

$80 \%$ of participants agreed that family factor plays a negative role on adults' ESL learning. As a participant complained:

My husband has been recently fighting with me over the money that I spent on the tuition fee. Even though I have already done all the housework, he is still not satisfied (QP E).

This view is similar to that of Bourgeois (1999, p. 90) who showed that "about half of students questioned stated that the major difficulty was the lack of time because of familial obligations". He thus concluded that the most common obstacles to adults' learning are the costs incurred and lack of time.

Many participants $(82 \%)$ indicated that the first language strongly interferes with adults' English learning. As a participant complained:

I often reply to a negative question in English in a wrong way, even though I know the correct answer clearly. When a friend meets me and says, 'I have not seen you for a long time'. I often answer 'yes'. My English teacher ever played a joke with me. He asked, 'are you Ting'? I answered, 'yes'. Then he asked, 'aren't you Ting?' I answered, 'NO, I AM 
Ting'. Because the logical grammar in Chinese is opposite to that in English, when I answer 'yes', it means that I agree with what my friend is saying that 'I have not seen you for a long time'. When I answered 'no', it means that I did not agree with what my teacher said that 'you are not Ting'. However, because I have been used to thinking in Chinese language, I can not change into the way of English thinking (QP F).

What are the Chinese adults' views on how to improve adults' ESL learning?

According to the responses to the open-ended questionnaires, having confidence was mentioned 10 times. This was the most frequently mentioned suggestion for improving adult ESL learning. As a participant responded:

I lost confidence in playing the piano ten years ago. Since I did not begin to play the piano until 17 years old, I felt I could not compete with those who started early like 4 or 5 years old. However, five years later, I was confident again because I found a girl who began to play at 5 years old but did not improve her skills highly when she grew up. Therefore, I concluded that if one does not study hard, even though long time has past, he/she cannot achieve more, while only if one contributes enough time and effort, can he/she succeed in learning (QP G).

This view was supported by Carroll and Du Shichun (as cited in Wu Biyu, 2005) who pointed out that the language ability one can reach is up to how long he/she has spent on the language study rather than when he/she began to learn, and how he/she spent the time in learning the language. Knox (1986, p. 21) also noted, "most adults, in fact, can learn almost anything they want to if they are willing to devote enough time and attention and if they receive some assistance".

Many participants (8) suggested that adult ESL learners should coordinate the family relationship and properly manage time for working and learning. As they responded:

They should explain clearly that the family can benefit greatly from learning English. The ESL learner can get a better job or be promoted by learning English. As a result, the salary and position will be more and higher than before. The ESL learner can also teach his/her children English at home. As their children do not have to join English night class, the tuition fee can be saved as well (QP H).

Adults should plan and write down the procedure of what they are going to do in the coming several days. This is very helpful for reminding adults what to do next. If people do not write down, they have to remember what to do, such as cleaning, cooking and going shopping. This will influence the memorization of learning. If people do not memorize a lot of trifling things, they can remember what they have learned better. I once complained that I had to forget things. I thought it would be great if I never forget what I had learned. Later, I read something about forgetting from a magazine. It says, 'we forget things in order to remember useful things better'. I then understood that if people did not forget, their head would be fulfilled over time. Therefore, I usually write down what I am going to do so that my head will have enough room for memorizing knowledge (QP I).

Adults should make use of short times like 5 or 10 minutes. Adults usually have a lot of things to do every day, such as house working and job working. It is hard for them to get a whole-day free time for learning. Therefore, they have to make use of short free times because these times can accumulate more (QP J).

Suggestions of that adults should consider the competition as a motivation to encourage them to study hard, rather than being stopped by the feelings of embarrassment, and that ESL adult learners should try their best to adjust to the way of English thinking during ESL, were mentioned 5 and 3 times respectively.

\section{RECOMMENDATIONS}

Based on the responses by Chinese adult ESL learners, recommendations are made to improve adults' ESL learning. They were listed as follows:

1. Adults should have confidence in ESL learning.

2. Adults should consider the competition as a motivation to encourage them to study hard, rather than being stopped by the feelings of embarrassment.

3. Adult ESL learners should coordinate the family relationship and properly manage time for working and learning.

4. ESL adult learners should try their best to adjust to the way of English thinking during ESL learning.

\section{CONCLUSION}

This study examined Chinese adult ESL learners' views on the reasons of their pursuing ESL learning, the advantages of ESL learning that adults may have over children, the problems of their ESL learning, and how to improve adults' ESL learning. The findings confirmed that adult education functions significantly in Chinese education. Adults' ESL learning especially plays an important role on the development of China and of the adults themselves. Although they may have some advantages over children, they did experience difficulties and problems when pursuing ESL learning. Many suggestions were also made to improve adults' ESL learning. This research could be further developed if the research to be undertaken in order to discover teaching approaches and learning strategies which best suit adults' real situation.

\section{APPENDIX}

\section{Questionnaire to examine challenges of Chinese adults' ESL learning.}


1) Part A: Please highlight only one choice.
1. Your native language: a. Chinese
b. English
2. Gender: a. Male
b. Female
3. Age: a. 18-24
b. 25-35
c. $36-50$
d. Over 50

4. Length of learning English as a second language (up to now):
a. Less than 12 months
b. Over one year to four years
c. Over four years to nine years
d. Over nine years

\section{Highest qualification completed}
a. High school
b. Certificate/Diploma
c. Bachelor degree
d. Masters degree
e. Doctoral degree f. Other(s) (please specify)

2) Part B: Please highlight your most appropriate response.

a) Directions: Please indicate your most appropriate response by using the following criteria:

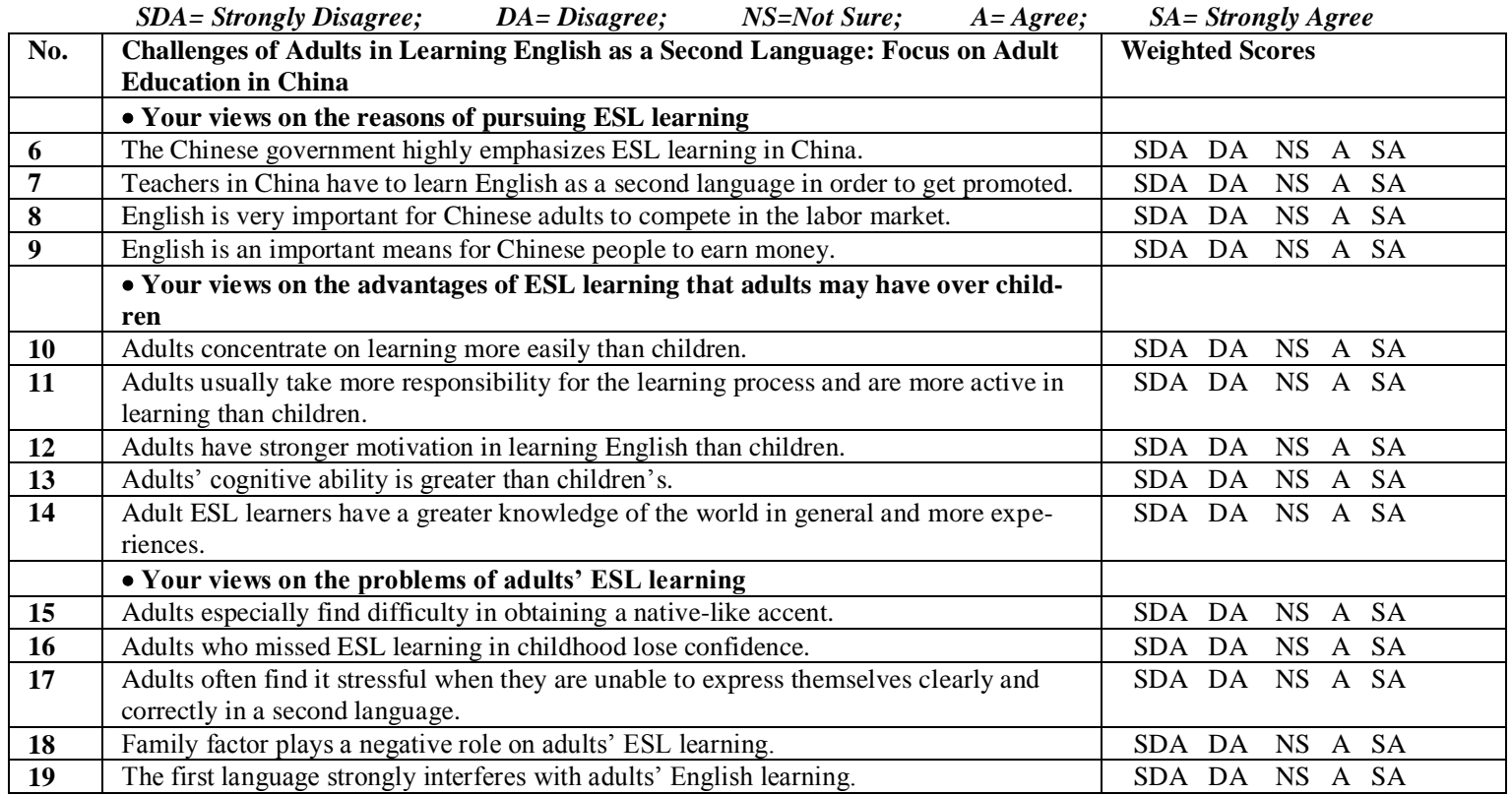

\section{Open-ended questions:}

1. Please write down any comments you would like to make regarding the reasons of Chinese adults' pursuing ESL learning.

2. Please write down any comments you would like to make regarding the advantages of ESL learning that adults may have over children.

3. Please write down any comments you would like to make regarding the problems of adults' ESL learning.

4. Please write down any comments you would like to make regarding how to improve adults' ESL learning.

\section{REFERENCES}

[1] Bourgeois, E. (1999). The Adult university. Buckingham: Society for Research into Higher Education \& Open University Press

[2] Brod, S. (1995). Outreach and retention in adult ESL programs. Washington, DC: National Clearinghouse for ESL Literacy Education.

[3] Brown, H. D. (1994). Teaching by principles: An interactive approach to language pedagogy. Upper Saddle River, N.J.: Prentice Hall Regents.

[4] Brown, H. D. (1991). Breaking the language barrier: Creating your own pathway to success. Yarmouth, ME: Intercultural Press

[5] California State Department of Education. (1993). English as a second language: Implementing effective adult education programs. Sacramento: California State Department of Education.

[6] Centre for Educational Research and Innovation (CERI) (1987). Adults in higher education. Paris, France: Organization for Economic Co-operation and Development.

[7] Crandall, J., \& Peyton, J. K. (Eds.). (1993). Approaches to adult ESL literacy instruction: Language in education. Washington, DC: ERIC Clearinghouse on Literacy Education for Limited-English-Proficient Adults.

[8] Cook, V. (1991). Second language learning and language teaching. London: Edward Arnold.

[9] Graddol, D. (2006). Learners of the future. B. B. C. Learning English. Retrieved June $2^{\text {nd }}, 2006$ from http://www.bbc.co.uk/worldservice/learningenglish/radio/specials/1720_ten_years/page9.shtml.

[10] Harmer, J. (1991). The Practice of English language teaching. London: Longman.

[11] Knox, A. B. (1986). Helping adults learn. San Francisco, Calif.: Jossey-Bass. 
[12] Levy, S., Osborn, M., \& Plunkett, M. (2003). An investigation of international students' academic and social transition requirements' Enhancing the transition to higher education: strategies and policies that work, proceedings of the Seventh Pacific Rim Conference [on] First Year in Higher Education, 9-11 July 2003, QUT, Brisbane, Australia, edited by D Nulty and N Meyers. Brisbane: Queensland University of Technology 2003.

[13] Lightbown, P. M. \& Spada, N. (1993). How languages are learned? Oxford: Oxford University Press.

[14] Little, D., McAllister, J. \& Priebe, R. (1991). Adult learning in vocational education. Geelong, Vic.: Deakin University.

[15] Norton Peirce, B. (1995). Social identity, investment and language learning. TESOL Quarterly, 29(1), 9-31.

[16] Norton Peirce, B. (2000). Identity and Language Learning: Gender, Ethnicity and Educational Change. Essex, United Kingdom: Pearson.

[17] Richard-Amato, P. A. (1996). Making it Happen: Interaction in the Second Language Classroom: From Theory to Practice. White Plains, NY: Longman.

[18] Ramirez, H. M. (1994). Literacy acquisition among second language learners. In B. M. Ferdman, R. M. Weber, \& A. G. Ramirez (Eds.), Literacy across language and cultures (pp. 75-101). Albany: State University of New York Press.

[19] Smoke, T. (Ed.) (1998). Adult ESL: Politics, pedagogy, and participation in classroom and community programs. Mahwah, NJ: Lawrence Erlbaum Assoc.

[20] Spencer-Oatey, H., \& Xiong, Z. (2006). Chinese students' psychological and sociocultural adjustments to Britain: An empirical study. Language, Culture and Curriculum, 19(1), 37-53. Retrieved April 1, 2008, from http://www.tandfonline.com/doi/pdf/10.1080/07908310608668753\#.UohW8BbWHFI.

[21] Ur, P. (1996). A Course in language teaching: Practice and theory. Cambridge [England]; New York: Cambridge University Press.

[22] Weinstein-Shr, G. (1993). Overview discussion: Directions in adult ESL literacy-An Invitation to dialogue. TESOL Quarterly, 27(3), 517-528.

[23] Wrigley, H. S., \& Guth, J. A. (1992). Bringing literacy to life: Issues and options in adult ESL literacy. San Mateo, CA: Aguirre.

[24] Wong, Lap Tuen (2001). The Needs analysis and characteristics of Chinese-speaking adult ESL learners. Language, Society, and Culture Journal, 9. June $2^{\text {nd }}$, 2006 from http://www.aaref.com.au/en/publications/journal/archived-articles/issue-09-2001.

[25] Wu, Biyu (2005). Studies on adults' advantages in learning English from the perspective of educational psychology. Journal of Urumqi Adult Education Institute, 13(2), 73-74. Retrieved June 2 $2^{\text {nd }}, 2006$ from http://dx.doi.org/10.3969\%2fj.issn.16715179.2005.02.023.

[26] Wu, Huifang (2002). Advantages and disadvantages of adults' English learning and the teaching methods. Educational Journal of Adult Higher Education, 4, 61-62.

[27] Wu, R. T. (2013). Non-English-Speaking International (NESI) Students' Tertiary Learning Strategies in Relation to English for Academic Purposes. Kuala Lumpur, Malaysia: Arab World English Journal. Retrieved November 24 ${ }^{\text {th }}$, 2013, from http://www.awej.org/images/Theseanddissertation/RuiTingWu/119\%20full\%20thesis.pdf.

[28] Xie, Guodong, \& Du, Yue. (2002). The Thinking of the international wiping off illiterates day. China Education and Research Network. Retrieved June $2^{\text {nd }}, 2006$ from http://www.edu.cn/20020903/3066271.shtml

[29] Zong, Shi (2002). The Great achievement of increasing working in wiping off Chinese illiterates. China Education and Research Network. Retrieved June $2^{\text {nd }}, 2006$ from http://www.edu.cn/20020909/3066962.shtml.

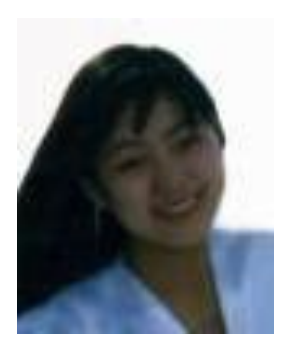

Ruijuan Wu, A lecturer in the Faculty of Visual Art, Qing Gong College, Hebei United University, Tang Shan, He Bei, China. She is also an artist in the area of Chinese traditional painting. Her research interest is visual art teaching and Higher education.

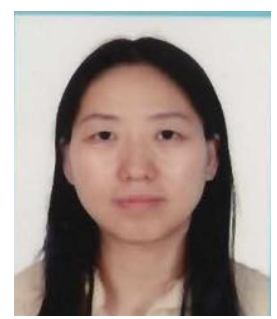

Ruiting Wu is an experienced School educator, having taught thousands of students from Prep to Year 12. Ms Wu holds a Bachelor of Teaching with Honours and a Master of Education in TESOL from the University of Tasmania, Australia. Her research interest is TESOL, primary teaching, and teaching Chinese as a second language. 


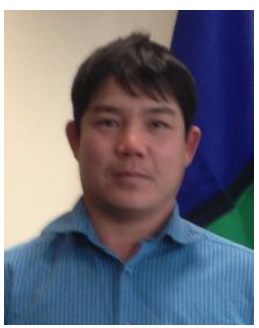

Van Tai Le A MBA student at the Tasmanian School of Business and Economics, University of Tasmania. Mr Le has completed a Bachelor degree in Aquaculture and a certificate IV of Supervision in Hospitality. His research interest is in the areas of Aquaculture, Economics, and TESOL. 